\title{
Sustainable Solutions for Fashion Design: Adjusting the Fashion Design Process for a More Sustainable Industry
}

\author{
Lavinia Ban \\ Design Department, Jeddah International College \\ Ibn Rasheed al Fehri, Taiba, Jeddah 23831, Kingdom of Saudi Arabia
}

\begin{abstract}
Fashion is a non-sustainable industry. One of the largest industries globally, fashion is considered one of the greatest polluters in the world - it contributes $10 \%$ of global greenhouse gas emissions, it generates nearly $20 \%$ of global water waste, and it produces yearly massive quantities of textile waste. Despite the efforts of researchers or pioneers at various levels of the industry, changes seem to take place slowly and isolated. Assuming that a real change in the industry must happen from the very initial stage of creation - the way we think and conceive fashion, this paper takes a closer look at the fashion design process. As studio-oriented research, the paper focuses on the designer's work and highlights the designer's responsibility during the multiple phases of creation. From concept development to materials sourcing, from recycling/re-using/repairing strategies to the new technologies of production, from slow fashion movement to multifunctional garments design - sustainable oriented actions must occur simultaneously at each stage of the design process. The conventional phases of fashion thinking are reevaluated, embedding sustainable concerns into the studio standard processes. Relevant solutions and examples of best practices are further illustrated and analyzed. Emphasizing the importance of seeing sustainability as an integrated part of the design process, the paper aims to adjust the fashion designer's mindset to function as a catalyst for the industry's transformation.
\end{abstract}

Keywords: sustainability, fashion design process, sustainable solutions, studio practice

DOI: $10.7176 / \mathrm{ADS} / 81-03$

Publication date:March $31^{\text {st }} 2020$

\section{Introduction}

Fashion is one of the largest industries globally - the global fashion industry values 3,000 billion dollars and 2 percent of the world's GDP (Fashion United). Fashion and textile industry is the third-biggest in the world following automotive and electronics manufacturing, and about 60 million to 75 million people are employed in the textile, clothing and footwear sector worldwide (Cleanclothes.org). Yet, the clothing and textile industry is the second largest polluter in the world after the oil industry.

Textile production involves lots of resources - producing, spinning and dyeing raw materials such as cotton uses huge amounts of water (nearly $20 \%$ of global water waste), while specific processes as leather tanning involve toxic chemicals that leach into the ecosystem. Materials such as polyester, nylon or acrylic are made out of fossil fuels and are not biodegradable. A significant quantity of micro-plastics is released into the water supply as clothes are washed over their lifetime, while denim chemical-intensive treatment produces toxic rivers harming communities around the world as revealed in the documentary "The RiverBlue: Can Fashion Save the Planet?". Moreover, the industry has a terrible environmental impact in the countries where garments are produced - the disasters like the Rana Plaza factory collapse in Bangladesh 2013 point out that our clothes are still made by "some of the poorest, most overworked and undervalued people in the world" (The Guardian). The growing of fast fashion in the last two decades increased the amount of discarded garments producing yearly a larger amount of waste. Millions of products developed with embedded obsolescence contradict the core values of sustainability. An EU report published in January 2019 found that only half of the used clothes are recycled, and only one percent of these are turned into new clothes (Dezeen). The vast majority is discarded or incinerated, releasing more carbon into the atmosphere.

Implementing a sustainable orientation in the fashion industry is mandatory, but obviously it is not an easy task. Therefore, it is important to understand how to link sustainability to fashion, and which are the areas of the industry that need to be fixed or re-imagined. Since the 1990s fashion attempts to enhance its sustainable features and to achieve an environment-friendly status. Changes take place slowly with more visible actions occurring in recent years.

But what is the deep meaning of sustainability? And why is it so uneasy to relate it to fashion? What is the difference between sustainable development and 'green fashion"?

The Brundtland Report (1987) defined sustainable development as that "which meets the need of the present without compromising the ability of future generations to meet their own needs". Considered from this perspective, fashion development contradicts the very essence of sustainability. Sandy Black (2008) refers to it as 'an oxymoron - the fashion paradox', as fashion is mainly governed by change and over-production, "economic imperatives and the transience of passing trends fuel a continuous cycle of production, consumption, and obsolescence, stimulated 
by desire and aspiration and far removed from basic clothing needs" (Black, 2010: 252).

Fashion is essentially about change and endless production - new clothes, new tastes, new colors, new fabrics, new ideas, a new look. Can fashion itself ever change? Where and how to intervene for a more environmentally friendly industry?

While sustainability is a central topic both in the academic and business environments, its meaning and implications are still misunderstood by many. Unlike popular terms in use such as "eco" or "green", sustainability is defined as a broader concept involving more than ethical concerns in the use of materials, but a variety of associated topics such as technology and innovation, product life cycle, the pace of fashion consumption, social fairness, supply chains, labor laws, etc.

Discussing sustainability in fashion covers a multitude of aspects, far beyond the use of eco-friendly materials or recycling policies. It relates to business models, to transparency in supply chain and production, fair labor, and social innovation, to a variety of players involved in the process of producing and selling fashion, it relates to the fashion image and advertising, to pricing and tagging, to the amount of work, creativity, and research encapsulated in a product, techniques, and technologies of fabrication, packaging, transportation, and more.

As the fashion industry is conventionally organized on four major levels (Stone, 2008): textile production, garment production, retailing and auxiliary services, sustainable strategies should be adopted at all levels of the industry - should cover material sourcing and manufacture sourcing, design and production, retailing and distribution, advertising, and promotion, etc. It also requires consumer engagement and collaboration, in terms of cultivating social responsibility.

\section{Fashion for Sustainability - Between Theory and Practice}

The short history of sustainability in fashion emerged during the 1970s as part of the hippie movement, started coagulating during the 1990s powered by pioneers like Katharine Hamnett, Esprit, and Patagonia, and had a breakthrough during the early 2000s when several designers and companies shifted to a more ethical approach in terms of materials use, recycling policies, fashion consumption, and outsourcing.

The new millennium saw the rise of designers and companies with genuine environmental concerns: Stella McCartney launching her eco-friendly label in 2001, Natalie Chanin founding Project Alabama, Christopher Raeburn creating garments from disposable parachutes, Suzanne Lee experimenting with lab-grown fabrics and coining the term BioCouture. Ethical fashion show was launched in London (2004), Esthetica (2006) started promoting ethical fashion labels, and global retailers like Marks \& Spencer launched their Look behind the label campaign (2006), raising awareness among customers.

In recent years a new generation of young designers - Eileen Fisher, Christoph Rumpf, Richard Quinn, Faustine Steinmetz, Sruli Recht, Marine Serre, and Sun Lee among others, started approaching fashion with a fundamentally different mindset, cultivating new ways of fashion thinking and fashion making. Future sounds more promising as luxury brands like Vivienne Westwood, Prada, Louis Vuitton reorient towards sustainability, global retailers like Puma and H\&M started collecting their used items, and ZARA pledges to sell only sustainable products by 2025 .

Since Naomi Klein's book, No Logo was published in 2000, and McDonough \& Braungart seminal text Cradle to Cradle: Remaking the Way We Make Things was published in 2002, many fashion academics focused their research on sustainability, seen as the only possible option for the future of the industry. Significant advances in fashion sustainable studies have been done through the contribution of researchers such as Fletcher $(2008,2010$, 2016), Black (2008, 2013 ed.), Clark (2008), Thorpe (2007), Hethorn \& Ulasewicz (2008), Giesen (2008), Gwilt (2014), Rissanen \& McQuillan (2016), Fletcher \& Grose (2012), Szmydke-Cacciapalle (2018), Esposito (2018).

Efforts of researchers and educators, and inspiring examples of best practice from the industry, should finally come together to outline a new way of fashion thinking. When it comes to fashion thinking, it is hard to imagine any change or paradigmatic shift without referring to the central act of fashion making - the designer's studio and the fashion design process.

\section{Fashion Designer's Mission}

Black (2008) and Fletcher (2008) are among the first scholars to explore ways in which fashion designers can engage with sustainability, while Alison Gwilt (2014) articulates a conceptual model where designers play the central role (Gwilt, 2012, 2014). Rissanen and Gwilt (2011) pointed out the necessity of integrating sustainable strategies in the fashion design process. In The Practical Guide to Sustainability (2014) Gwilt stresses for a sustainable approach in each phase of the design process providing a holistic view on fashion designer's practice, and the ways it can be optimized for a better future.

Moreover, a young generation of fashion designers, most of them graduating from leading fashion schools around the world - CSM, Parsons, UAL, SCAD, etc., started developing a different approach to fashion design. They are heeding sustainability as an essential benchmark in their fashion projects.

Richard Quinn, a CSM graduate who recently won the H\&M's Design Award, argues that “you can't be a 
designer now without being sustainable and socially aware." Quinn used his prize to invest in a digital printing workshop which requires $70 \%$ less water and $80 \%$ less energy than traditional techniques allowing him to produce fabrics in the precise quantities he needs and thus eliminating waste (Vogue UK).

Faustine Steinmetz, the initiator of "denim couture", notes that "At first I really set out to be a sustainable label, but I came to the conclusion, when I was doing my research, that nothing is sustainable. You can only be responsible" (Vogue).

Australian designer Courtney Holm, the creator of A.BCH (a label aiming to be sustainable from every angle), observes that "If you're not thinking about the end of life of a product in the design stage that's incomplete design" as "Recycling is not the answer... it's [just] one of the things we can do" (Commonobjective).

Designer Martine Jarlgaard, who is pioneering transparency in fashion supply chain explains that "Shaping a brand and a voice brave enough to step away from fashion as we know it" inspired her to start up a fashion business based on sustainable principles. She states that a new approach will "fundamentally change the way we define value, consume, communicate and interact" (Thelissome).

While these designers seem to understand the value of sustainable products and adopt an environmentally friendly approach fully integrated into their work process and brand philosophy, many professionals keep referring to green solutions as an additional feature or isolated experiments separate from their main lines.

This paper aims to outline the fashion designer's input in the movement for a more sustainable industry thus it focuses on the fashion design creative process. Situated at the intersection of many other relevant operations - material sourcing, pattern making, technology and innovation, product development and presentation, production and distribution solutions, designer's work encapsulates the philosophy of fashion making, and has a significant impact on the way we see, consume, wear, and experience fashion.

As shown above, sustainable fashion is a very broad subject that covers many areas of investigation and requires a variety of actions to be taken at many levels of the industry. The intention here is to focus on fashion design practice and designers' involvement in sustainable strategies that can make a difference.

How can designers bring sustainability to the industry? How can designers learn about these strategies and eventually develop a different mindset? How can they integrate sustainability into their daily practice? How can they make a real impact on the industry?

Sustainability cannot be regarded anymore as an isolated feature, or an option. It is not a design afterthought. It has to be part of the design process and embedded in every phase of conception, production and marketing new products. Fashion designers play a crucial role in the sustainable development of the future. As McDonough argues - 'fashion is a verb', and fashion designers are capable of fashioning the future. "To fashion is to make, and the way we fashion things (from buildings to products, clothes and accessories) will fashion the world we live in" (Hethorn \& Ulasewicz, 2008: xviii).

During the last decade, a few academics have succeeded to articulate a theoretical framework aiming to redefine designers' role and mindset to generate more sustainable solutions. While this direction needs to be pursued further to eventually become a norm, new principles and guidelines for designers need to be clearly articulated and successfully implemented in the fashion practice and supported by fashion education.

Back to the fashion design work process, a deeper analysis is required. As we know, the fashion industry employs a variety of professionals that all participate and contribute to the process of creation: designers, buyers, pattern makers, machinists, knitters, textile designers, engineers, finishers and dyers, product developers, production managers, and so on. As the design process is a result of teamwork, precious input can be acquired at each and every phase. The designer plays a crucial role as the one who orchestrates the concept and development of new products, setting the parameters for the other members of the team - what type of materials to use, what type of technologies, what type of products, etc.

Researchers such as Van Dyck (2008) or Fletcher \& Grose (2012) address the designer's role, which can be challenged in the near future, to enable him to act as 'an agent of change' and to assume a leadership position. Gwilt (2014) and Rissanen (2016) state that sustainability in fashion depends on the designer to lead the creative process. Regarded as 'the critical link' in the chain of design and production, fashion designers "have both the ability and the opportunity to develop products that can lessen our impact on the environment while addressing social and ethical concerns" (Gwilt, 2014: 10). If so, what are the knowledge and skills designers need to master?

Future designers need to get more knowledge about eco-materials and sustainable technologies, digital fabrication as well as an appreciation for crafts and slow fashion, ethical sourcing and manufacturing, consumer behavior, marketing and merchandising new directions, etc. They need the skills to design integrated products and services, to combine economic and environmental interests by designing new relationships between them. This requires a holistic view of creation, sourcing, production and distribution processes. As pointed out by Vezzoli \& Manzini (2008: 212) "it is not so much the technical details of the products as the relationships between different stakeholders that have to be designed."

A fashion thinking that integrates sustainable concerns requires designer's involvement in sourcing, in selecting fabrics and finishing techniques, in garments construction and manufacturing processes, in collaborating 
with patternmakers, technicians, product developers, etc. It requires an increased focus on customer habits and needs: how their customers purchase, how they wear the pieces, how they care and maintain them, how they discard them, etc. Designers can further contribute to educating their customers.

Although there are many aspects of the fashion design process and related production activities to be addressed for making a real change, few references are available for designers to show them how to work and how to integrate sustainable strategies in their studio process.

Sandy Black brings together a number of strategies that have been suggested by design theorists and practitioners, showing how they can work simultaneously to make a significant change in design and consumption behaviors. Black refers to adjustments in the fashion practice and outlines the main areas of the design process to be challenged:

- Designing for longer life and ease of disassembly of component parts

- Simplifying the use of materials in a product, avoiding blended fiber, considering recycling

- Developing close loop processes aiming to eliminate waste

- Promoting new technologies for innovation, increasing efficiency and reducing the environmental impact

- Re-thinking the way fashion is designed, produced and distributed

- Creating higher-quality pieces with longer life expectancy, thus reducing obsolescence in fashion

- Re-using and recycling in innovative ways

- Slowing-down the fashion cycle to create more valuable design pieces

- Promoting new services which extend the life of fashion items, such as renting, repairing, re-designing

- Creating infrastructure for new types of recycling to clean the landfills by reusing of waste materials (Black, 2010, 259)

Further pursuing Black's perspective, a few scholars have the merit of exploring more in-depth the possible applications of some of these strategies in the fashion design process.

A Practical Guide to Sustainable Fashion (2014) points out that fashion designers must "understand the key phases within the life cycle of a garment and that, armed with this knowledge, it becomes possible to improve a garment's environmental and ethical credentials" (Gwilt, 2014: 7). The book explores a variety of ways in which designers can bring sustainability into the fashion design process. Exploring each key phase of the garment life cycle: design, production, distribution, use, and end-of-life, it proposes design strategies to be integrated into the design process, connecting them with examples of best practices from contemporary fashion.

In Zero Waste Fashion (2016) Rissanen \& McQuillan focus on creative methods to eliminate fabric waste from garment production. Considering that a 10 to 20 percent of the fabric used for garments design is swept off the cutting-room floor, the authors argue that the waste could be dramatically reduced through creative design thinking and collaboration. Noting a gap in fashion practice fueled by an education that keeps designers and technicians divided into a counter-productive and rigid system hierarchy, Rissanen challenges designers to rethink their creative process, especially their relationship with pattern cutters. To eliminate waste, Rissanen stresses that "the technical and visual elements of a garment need to be considered simultaneously" (Hethorn \& Ulasewicz, 2008: 184).

Despite significant progress in isolated parts of the industry, the majority of fashion designers tend to regard sustainability as an afterthought of their design practice. Contemporary fashion education continues to promote a traditional method of fashion design practice, which fails to integrate sustainability as an essential requirement for any successful design. Designers of tomorrow should be educated in principles of design practice and well informed about sustainable strategies: conceptual approach, materials use, manufacturing techniques, new technologies, product life cycle design, etc. They have to learn especially how to bring all these aspects together and handle them simultaneously to make them work for a common goal.

A cross-disciplinary dialogue would also be beneficial. Fashion designers must broaden their perspectives, collaborating with industrial designers, architects, engineers, chemists, etc. "The Cabbage Chair" (2008) designed by Nendo for an exhibition curated by Issey Miyake is a relevant example developed at the intersection of textile and furniture design. The chair was conceived by re-purposing an unwanted by-product waste, the pleated paper used in mass amounts during the process of pleating fabric for fashion.

\section{Integrating Sustainability in the Studio-based Fashion Practice}

Let's take a closer look at the designer's work and the studio processes that lead to new fashion developments. The typical stages of creation are investigated and analyzed in a variety of academic textbooks. Stecker (1996), Asperlund (2015), Rotham (2016), Sorger \& Udale (2017), Renfrew \& Renfrew (2009), Jennings (2011), Dieffenbacher (2013), Brannon (2011), document the fashion design process and explore in-depth key phases of creation from inspiration and concept development to prototyping and the final product.

While all agree on a generic sequence of steps and studio activities typical for the fashion design process, investigating each of them in detail, the sustainable concerns remain marginal in most of the manuals or handbooks. 
As our focus here is to bring sustainability into the spotlight, we will revise these multiple phases of creation by intertwining the sustainable concerns in the designer's work process.

In his study on design process, Aspelund (2015) identified seven stages of design process: Inspiration, Identification, Conceptualization, Exploration/Refinement, Definition/Modeling, Communication, Production. Referring to the fashion design process, Dieffenbacher (2013) proposes a simplified model of designer's thought process, covering three crucial steps: Idea, Concept, Design.

While a fashion design process can be investigated by breaking it down in stages, many practicians agree that there is no clear-cut boundary between these stages of creation. As most of the time the phases of the design process overlap or occur simultaneously, the fashion process implies a series of interlocking decisions.

However, the main phases of the fashion design process, no matter how they are labeled by various practicians or researchers, must cover essential dimensions of the studio work that impact on the final designs. The terminology proposed here covers the cornerstones of any fashion design process: the theme and inspiration, the concept development, the materials, the techniques and technologies involved, 3D exercises and prototyping, finishing, product further developments, and presentation.

These phases initiated in the designer's studio and carried on further to the production stage (when industrial production applies), will be labeled here as:

- Inspiration and concept development

- Materials sourcing

- 3D experiments / Prototyping

- Production sourcing

- Further product developments and presentation

Inspiration and concept development refer to a designer's thought process and ideas that will be shaped into products. Material sourcing refers to the fabrics and accessories designers use in their collection or choose to develop themselves. Prototyping implies 3D exercises that convert materials in garment shape through various construction techniques: cutting, stitching, full-fashioned, 3D printed, etc. Production sourcing covers the conditions for the designs to be manufactured. Product developments and presentations refer to advanced features, embedded services, retailing and distribution, end of life strategies that may add value to the product.

This paper addresses sustainable strategies and actions taking place during the fashion making of, as the only possible approach for a genuine re-orientation in the field. Taking a closer look at the phases of the designer's creative process, it shows where and how design decisions can affect the evolution of products and services to achieve optimal results. It also shows how these decisions are interdependent. At each stage of the fashion design process, designers should consider the sustainable strategies that can lead them to an improved and better product (Table.1).

Table 1. Stages of fashion design process and the related sustainable strategies.

\begin{tabular}{|c|c|}
\hline $\begin{array}{l}\text { RELEVANT STAGES OF } \\
\text { CREATIVE PROCESS }\end{array}$ & $\begin{array}{l}\text { EXAMPLES OF SUSTAINABLE STRATEGIES THAT CAN BE APPLIED at each } \\
\text { stage of creation }\end{array}$ \\
\hline $\begin{array}{l}\text { Inspiration and concept } \\
\text { development }\end{array}$ & $\begin{array}{ll}\text { - } & \text { Slow fashion (e.g. valuable, timeless designs) } \\
\text { - } & \text { Smart product design (e.g. multifunctional, convertible) } \\
\text { - } & \text { Customized products and services } \\
\end{array}$ \\
\hline Materials sourcing & $\begin{array}{l}\text { - } \quad \text { Considerations about location, and transportation } \\
\text { - } \quad \text { Recycling, up-cycling, re-purposing } \\
\text { - } \quad \text { Using ethical materials and textile technologies } \\
\text { - } \quad \text { Developing new textile design solutions }\end{array}$ \\
\hline $\begin{array}{l}\text { 3D experiments / } \\
\text { Prototyping }\end{array}$ & $\begin{array}{l}\text { - } \quad \text { Developing smart cutting techniques (e.g. zero waste) } \\
\text { - } \quad \text { Full fashioned garments } \\
\text { - } \\
\text { - } \\
\text { Expeloping smart assembling technique (e.g. compact, modular) } \\
\text { Eximg with alternative techniques (e.g. digital fabrication) }\end{array}$ \\
\hline Production sourcing & $\begin{array}{l}\text { - Considerations about location, and transportation } \\
\text { - Considerations about social fairness (e.g. the amount of work put in the } \\
\text { piece and the way it was rewarded, working environment, labor laws) } \\
\text { - Strategies that can add value to the product (e.g. craftsmanship, supporting } \\
\text { local communities, exploring environmental friendly hi-tech solutions) } \\
\text { - Close loop production }\end{array}$ \\
\hline $\begin{array}{l}\text { Product development \& } \\
\text { presentation }\end{array}$ & $\begin{array}{ll}\text { - } & \text { Innovations in retailing (e.g. supply chain transparency) } \\
\text { - } & \text { Care directions, reparation, maintenance, customer assistance } \\
\text { - } & \text { Product end-of-life concerns (e.g. strategies for recycling, collecting used } \\
& \text { pieces, re-use or re-purpose) } \\
\text { - } \quad \text { Exploring smart packaging and smart tagging }\end{array}$ \\
\hline
\end{tabular}


Sustainable strategies must be embedded in the design process the same way the trends-style-color-rhythmproportion, and functional features are. Moreover, sustainability became a key parameter in evaluating a successful design in the 21 st century. The notion of the design itself gained complex values, and nowadays, to design, by definition, means to get attuned to people and the environment (Walker \& Giard, 2013).

Sustainable considerations can be included in any phase of the process, or in all of them simultaneously. However, the relationship and the sequence of these phases varies a lot from one process to the other. As we already know, some designers may get their inspiration from the textile fabric or particular production techniques, some may prioritize customer needs. Designers using traditional prototyping techniques may engage in 3D experiments differently than designers exploring digital fabrication or other innovative production technologies.

There is no universal recipe for being creative or accomplishing a project, but certainly all the phases of the design process have to be considered as interconnected. As each phase is related to the other and sometimes happens simultaneously, the fashion designers need to take a more holistic approach. Thus, instead of seeing the fashion design process as a linear development (Figure.1), it is more suitable to understand it as a complex cycle (Figure.2).

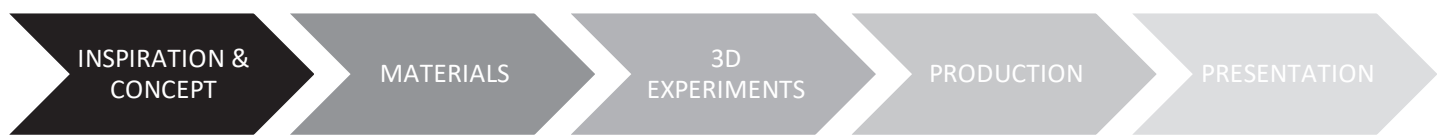

Figure.1.The fashion design process conventionally regarded as a linear evolution, from inspiration to the final product

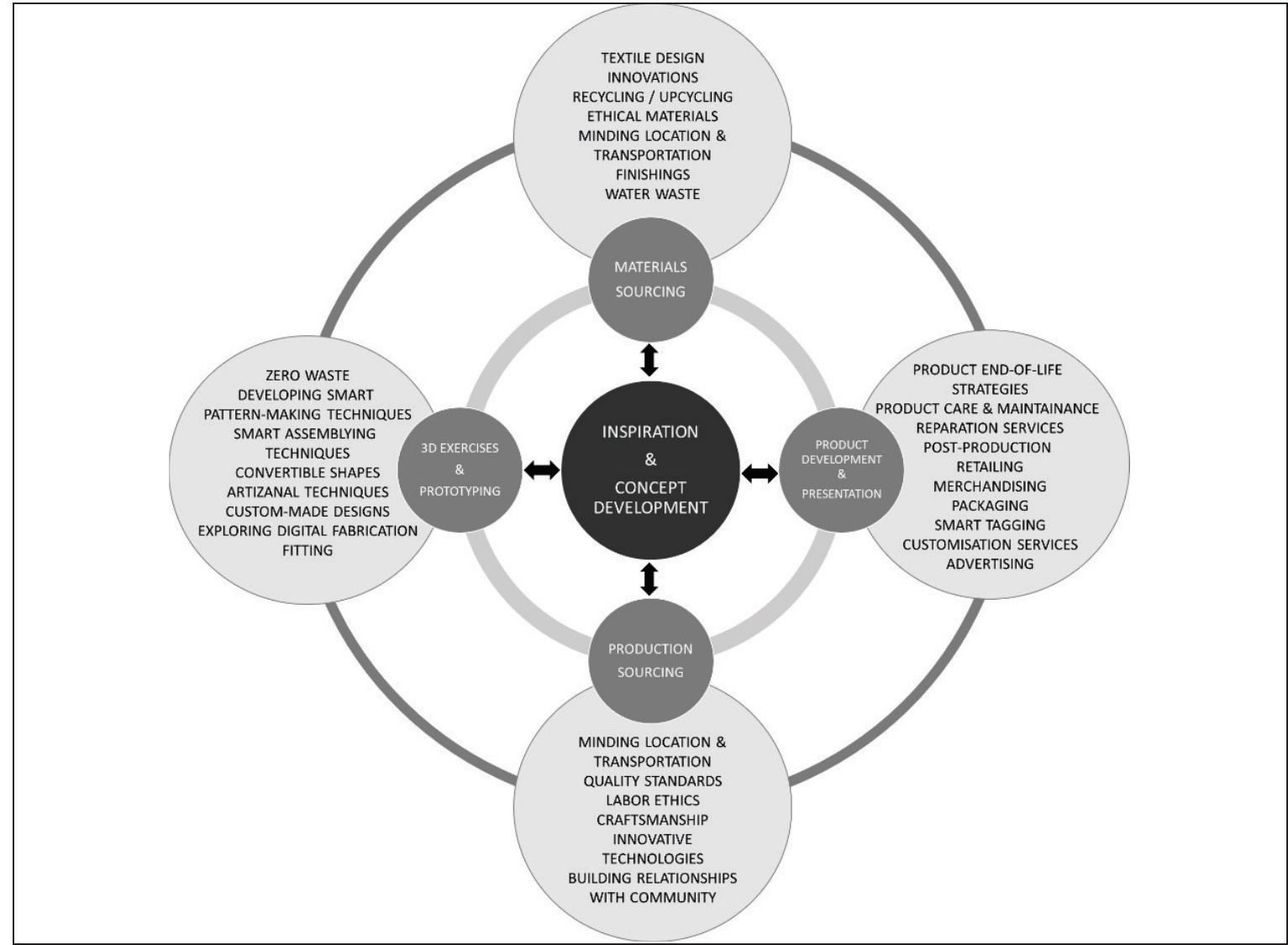

Figure.2.The fashion design process regarded as a complex radial evolution in which all stages are interconnected and interdependent

Inspiration and concept development phase is considered here as the core of the fashion design process, as it fuels all the other aspects of conception and production while being simultaneously conditioned and heavily influenced by them (Figure.2). Placed in the center of any process or creative activity, inspiration evolves in complex concepts that influence the nature of any project. Moreover, inspiration is always related to materials, production, technology, and customers' needs.

Considering the diagram in Figure. 2 as a framework, a series of fashion examples are analyzed below, 
indicating various ways designers can apply sustainable strategies in their projects. The sustainable strategies adopted in each of the examples analyzed are fully integrated into the fashion work process, at various phases of development from concept to final product. The analysis results are displayed in Table 2.

\subsection{Ancuta Sarca - Upcycling old Nike sneakers}

Romanian designer Ancuta Sarca upcycles old Nike sneakers to transform them into new fashionable products. Reworking an iconic item, the designer found a personal way to re-purpose the sneaker elements and convert them in one-of-a-kind kitten heel fancy shoes. This way the old pair of shoes saved from landfills become precious material to be successfully re-integrated in new designs.

\subsection{Nervous system - Kinematics Dress}

Using Kinematics - Nervous System's 4D printing system that creates complex, foldable forms composed of modules - designers Jessica Rosenkrantz and Jesse Louis-Rosenberg created a completely wearable dress printed in one single folded piece. Composed of thousands of unique interlocking components, each dress is $3 \mathrm{D}$ printed as a single piece and requires no assembly. The Kinematics Dress represents a new approach to manufacturing that tightly integrates design, simulation, and digital fabrication to create complex, customized products. Experimenting with new technologies like digital fabrication can save a lot of material and energy waste, improving the ethical features of a fashion product and cultivating new aesthetical ideals in fashion.

\subsection{Ji Won Choi-Excessivism}

For her graduation collection at Parsons, Ji Won Choi designed fashion items that can be reconfigured in various ways. As an alternative to disposable "trendy" items that consumers wear once and throw away, Choi explores the concept of "sustainable wardrobe" and focuses on the development of multifunctional garments. Aiming to achieve enduring pieces evolving beyond seasonal trends, Choi experiments with bold color blocks, geometric shapes, and flexible closure systems. The garments easily mix and match, to be worn in multiple ways. Various elements within her garments can easily be manipulated to create multiple silhouettes; thus, creating more options to wear and achieving a more compact wardrobe (Vogue).

\subsection{For Days}

Sustainable fashion startup For Days goes beyond designing fashionable products and managed to set up a closedloop fashion system, which aims to avoid waste by endlessly recycling materials. An organic T-shirt or sweatshirt from For Days costs $\$ 38$ and provides the customer with a lifetime membership. A worn-out T-shirt will be replaced with a new one for \$8. All the returned items are recycled in For Days' manufacturing plant in Los Angeles. Old pieces are chopped up and reinforced with new material before being spun back into yarn for new fabric to make new products. For Days members can accumulate credit points to use for the future purchases or every time they return used pieces.

\subsection{Faustine Steinmetz}

The concept of Slow Fashion refers to the creation of durable, high-quality products that can overpass the rapidly changing trends in fashion. Faustine Steinmetz, well-known for her exquisite denim pieces, promotes the concept of "slow denim". Through her designs, produced from recycled materials using recycled water, Steinmetz strives to minimize the environmental impact of her products. Every piece is entirely worked by the designer with her team - from spinning, dyeing, weaving, and sewing, to sophisticated embroidery techniques or crystal embellishments.

\subsection{Sun Lee - Consumption of Heritage}

South Korean designer Sun Lee (a graduate from Design Academy Eindhoven) creates fashion lines out of traditional Korean paper. Consumption of Heritage is a collection "based on three principles of ephemerality, disposability, and sustainability" (Dezeen). Sun Lee uses the traditional Korean paper (hanji paper), which has been cut, torn and rolled by hand to create stunning modular fashion pieces that can be layered and styled in various ways. The garments feature elaborate textures and cut-out patterns and can be easily recycled.

\subsection{Marloes ten Bhomer-Rapidprototypedshoe}

The term Life cycle refers to the journey of a product from the extraction of the raw fiber to the point of its disposal. Some pieces can be recycled after use, some can be repaired or re-purposed. Rapidprototypedshoe, designed by Marloes ten Bhomer, and produced using Objet multi-material 3D printing, is conceived as a modular piece that can be dismantled and reassembled to replace the used parts. The concept of the shoe relies on the idea of removing the assembly work in Rapid Manufacturing. 
4.8 Martine Jarlgaard $x$ Provenance

Designer Martine Jarlgaard investigates ways to extend the value of a physical product through tools that facilitate transparency and sustainability. In partnership with blockchain technology company Provenance, she developed a strategy to track each step of the journey of a fashion item from raw material through the supply chain and finally to finished garment. Each step of the process is registered and tracked on the blockchain via the Provenance app, which customers could access by scanning a QR code found on the garment's label. The technology, which allows each step in the manufacturing process to be recorded with time and location stamps, innovates by bringing groundbreaking technology to the fingertips of customers who are looking for transparency in fashion. This is achieved through smart labeling such as NFC tags or custom plug-ins for e-commerce. The first garment ever tracked using blockchain technology was presented at the Copenhagen Fashion Summit's 'Solutions Lab' in Denmark, May 2017.

\subsection{Taylor Stitch - Restitch}

Taylor Stitch menswear takes a multidimensional approach to reduce fashion waste. Each Taylor Stitch garment is made from 95 percent recycled cotton, along with pre-used merino wool, and industrial hemp. Moreover, they built a crowdfunding platform to involve their customers in the product creation process. Each piece is designed to be as hard-wearing as possible. Taylor Stitch initiated the "Restitch" program, which collects the worn out pieces, to clean them, repair and eventually turn them into new-designs to be re-sold.

\subsection{Timo Rissanen - Zero waste fashion}

With Zero Waste Fashion, Timo Rissanen explores creative methods to eliminate fabric waste from garment production. Considering the 10 to 20 percent of the fabric waste occurs during the process of garments making, the designer aims to develop new methods to reduce waste through creative design thinking and

Table 2. The summary of examples of best practices analyzed, indicating the sustainable strategies integrated into the fashion design process

\begin{tabular}{|c|c|c|}
\hline & Designer focus / Project analyzed & Sustainable strategies applied \\
\hline \multirow[t]{2}{*}{1.} & \multirow{2}{*}{$\begin{array}{l}\text { Ancuta Sarca - Upcycling old Nike } \\
\text { sneakers }\end{array}$} & Recycling, Up-cycling, Re-purposing \\
\hline & & Re-Design \\
\hline \multirow[t]{3}{*}{2.} & \multirow[t]{3}{*}{ Nervous system - Kinematics Dress } & Innovative construction techniques - Digital fabrication \\
\hline & & Customized products and services \\
\hline & & Developing design alternatives for a new fashion \\
\hline \multirow[t]{2}{*}{3.} & \multirow[t]{2}{*}{ Ji Won Choi - Excessivism } & Smart product design -Multifunctional garments \\
\hline & & Slow fashion \\
\hline \multirow[t]{5}{*}{4.} & \multirow[t]{5}{*}{ For Days } & Considerations about location and transportation \\
\hline & & Close loop production \\
\hline & & Product end-of-life concerns \\
\hline & & Customer assistance and engagement in sustainability \\
\hline & & Recycling \\
\hline \multirow[t]{4}{*}{5.} & \multirow[t]{4}{*}{ Faustine Steinmetz } & Slow fashion \\
\hline & & Recycling \\
\hline & & Exquisite craftsmanship \\
\hline & & Developing new materials and textile design solutions \\
\hline \multirow[t]{3}{*}{6.} & \multirow[t]{3}{*}{ Sun Lee - Consumption of Heritage } & Exploring new materials and textile design solutions \\
\hline & & Exploring environmental friendly hi-tech solutions \\
\hline & & Product end-of-life concerns \\
\hline \multirow[t]{3}{*}{7.} & \multirow{3}{*}{$\begin{array}{lcc}\text { Marloes } & \text { ten } & \text { Bhomer } \\
\text { Rapidprototypedshoe } & & \end{array}$} & Smart assembling techniques - Modular design \\
\hline & & Digital fabrication \\
\hline & & Product end-of-life concerns \\
\hline \multirow[t]{4}{*}{8.} & \multirow[t]{4}{*}{ Martine Jarlgaard x Provenance } & Considerations about social fairness \\
\hline & & Innovative technologies in presentation and retailing \\
\hline & & Supply chain transparency \\
\hline & & Smart tagging \\
\hline \multirow[t]{4}{*}{9.} & \multirow[t]{4}{*}{ Taylor Stitch - Restitch } & Recycling, Repairing, Re-purposing \\
\hline & & Re-Design \\
\hline & & Product end-of-life concerns \\
\hline & & Customer assistance and engagement in sustainability \\
\hline \multirow[t]{2}{*}{10.} & \multirow[t]{2}{*}{ Timo Rissanen } & Experimenting with alternative garment construction techniques \\
\hline & & Zero waste fashion \\
\hline
\end{tabular}

team collaboration. Noting a gap in fashion practice fueled by an education that keeps designers and 
technicians divided into a counter-productive and rigid system hierarchy, Rissanen encourages designers to rethink their creative process and their relationship with pattern makers. To eliminate waste, Rissanen explores a variety of pattern-making and cutting techniques using the full width of fabric with minimal interventions. The results are creative and often surprising.

\section{Conclusion}

Sustainability in fashion cannot be achieved by undertaking isolated actions in various parts of the industry. It requires a paradigmatic shift - a major change to shake the industry, and the entire fashion system. Sustainable development requires a holistic approach covering simultaneously all the levels of the industry.

Working with diversified teams to constantly expand their vision, fashion designers can adjust the fashion design process for a more sustainable industry. As the fashion design process is closely linked to all significant operations that define the industry: materials and production sourcing, retailing, product further developments, presentation, etc., designers are responsible to cultivate sustainability in fashion.

Sustainable thinking cannot be regarded anymore as an afterthought, an additional feature, or a smart finishing for elitist products. It has to be embedded in the core process of fashion making and eventually become the norm. Being directly involved in the process of fashion making, designers are the key-players of the upcoming change.

Implementing a sustainable philosophy requires a full reconfiguration of the design thought process. Analyzing the phases of the fashion studio processes, we have shown how sustainability can be integrated at all design stages and, most important that must be embedded there from the very beginning - from the inspiration stage to project concept development. The multiple examples from the industry analyzed here demonstrate how designing with a sustainable mindset leads to a different type of products and services, generating a significant change.

To conclude, here are a few essential considerations. Firstly, designers need to be informed about these strategies and the connections between them. Secondly, they need to learn how to explore or prioritize them at various phases of their work process. Thirdly, important design decisions for sustainability are always made inside the design process, not separate from it.

A brand new, more promising era opens for the fashion world. The greatest challenge is to move to a new model of creating, producing, and consuming fashion. Fashion designers have the opportunity to make an impact on the industry, to re-imagine a new fashion environment, and to inspire future lifestyles.

\section{References}

Anderson, K., 2016. “The Struggle for Sustainability: One of Fashion's Most Exciting New Designers Speaks Out”, April 2016, Vogue.com, retrieved 19 Dec 2019.

Aspelund, K., 2015. The Design Process, Fairchild Books Library, eBook, 3rd edition.

Black, S., 2008. Eco-chic: The Fashion Paradox, Black Dog Publishing, London.

Black, S., 2010. "Ethical, Fashion and Ecofashion", 251-260, in Valerie Steele (Ed.), The Berg Companion to Fashion, Berg, Oxford and New York.

Black, S., 2012. The Sustainable Fashion Handbook, Thames \& Hudson, London.

Blanchard, T., 2019. "Who made my clothes? Stand up for workers' rights with Fashion Revolution week", April 2019, Theguardian.com, retrieved 19.12.2019.

Block, I., 2019. "Six fashion brands making the industry more sustainable", September 2019, Dezeen.com, retrieved 10.12.2019.

Clark, H., 2008. "Slow + Fashion - an Oxymoron - or a Promise for the Future...?" in Fashion Theory: The Journal of Dress, Body and Culture, Volume 12, Issue 4, Berg: Oxford and New York, 427-446.

Clark-Esposito, D., 2018. A Practical Guide to Fashion Law and Compliance, Fairchild Books Bloomsbury, New York.

Dieffenbacher, F., 2013. Fashion Thinking Creative Approaches to the Design Process, AVA Publishing, Lausanne.

"Discussing The Role Of Technology In The Future Of Fashion With Martine Jarlgaard", Thelissome.com, retrieved 19.12.2019

Fletcher, K., 2008. Sustainable Fashion and Textiles: Design Journeys, Earthscan Publications Ltd.

Fletcher, K., 2010. "Slow Fashion: an invitation for systems change", in Journal of Fashion Practice, 2 (2), 259266.

Fletcher, K., Grose, L., 2012. Fashion and Sustainability: Design for Change, Laurence King Publishing, London. Fletcher, K., 2016. Craft of Use: Post-Growth Fashion, Routledge, Abingdon and New York.

Giesen, B., 2008. Ethical Clothing: New Awareness or Fading Fashion Trend, Saarbrucken: VDM Verlag, Riga. “Global fashion industry statistics - International apparel”. Fashionunited.com, n.d., retrieved 10.08.2019.

Gwilt, A., 2014. A Practical Guide to Sustainable Fashion, Fairchild Books, Bloomsbury, eBook.

Gwilt, A., Rissanen, T. (Eds), 2011. Shaping Sustainable Future: Changing the Way We Make Things, Earthscan 
Publications Ltd.

Gwilt, A., 2012. "Integrating sustainable strategies in the fashion design process: A conceptual model of the fashion designer in haute couture" (Doctoral Thesis), RMIT University.

Hethorn J., Ulasewicz, C. (Eds.), 2008. Sustainable Fashion: What's Next? A Conversation about Issues, Practices and Possibilities, Fairchild Book Library, eBook.

"Increasing transparency in fashion with blockchain", Provenance.org, retrieved 30.08.2019.

Kim, H. E., 2015. "A Study on the Characteristics and Trends of Sustainable Fashion through Esthetica at London Fashion Week”, in Fashion \& Textile Research Journal. 2015. Apr, 17(2): 168-177.

McDonough, W., Braungart, M., 2002. Cradle to Cradle: Remaking the Way We Make Things, North Point Press, New York.

Phelps, N., 2017. "This Parsons x Kering Empowering Imagination Finalist Is Tackling the Excesses of Overconsumption Head On”, May 2017, Vogue.com, retrieved 19.12 2019.

"Podcast: A.BCH's Courtney Holm On Building A Circular Fashion Label”, Commonobjective.co, retrieved 11.12.2019.

Rissanen, T., McQuillan, H., 2016, Zero-Waste Fashion, Fairchild Books, Bloomsbury.

Singer, O., 2018. “The Young Designers Pioneering A Sustainable Fashion Revolution”, April 2018, Vogue.co.uk, retrieved 10.12.2019.

Sorger R., Udale, J., 2017. The Fundamentals of Fashion Design, Bloomsbury Visual Arts, London.

Stone, E., 2004. Dynamics of Fashion, Fairchild Books, New York, 2nd edition.

Stotz, L., Kane, G., 2015. "Clean Clothes Campaign, Facts on The Global Garment Industry", Cleanclothes.org, retrieved 23.08.2019.

Vezzoli, C., Manzini, E., 2008. Design for Environmental Sustainability, Springer-Verlag, New York.

Walker, S., Giard, J. (Eds.), 2013. The Handbook for Sustainability, Bloomsbury Academic, London.

Wilhide, E. (ed.), 2016. Design: The Whole Story, Thames \& Hudson, London.

"5 planet-friendly fashion brands changing the sustainability game", I-d.vice.com, retrieved 4.08.2019.

\section{Author: Lavinia Ban}

Born 1980, Oradea, Romania.

PhD (2012), Arts and Design - Fashion Design, University of Art and Design, Cluj-Napoca, Romania.

Assistant Professor of Fashion Design and Head of Design Department, Jeddah International College, Saudi Arabia (2016).

Areas of interest \& research: Fashion Design Process, Fashion Education, Fashion Cultural Studies, The Bodily Dimension of Fashion, Future Fashions, Sustainable Fashion. 